\title{
Hematological biomarkers for predicting carotid artery vasospasm during carotid stenting
}

\author{
Yusuf Can, Ibrahim Kocayigit
}

Department of Cardiology, University of Sakarya, Sakarya, Turkey

Submitted: 29 February 2020

Accepted: 18 June 2020

Arch Med Sci Atheroscler Dis 2020; 5: e206-e211

DOI: https://doi.org/10.5114/amsad.2020.97722

Copyright @ 2020 Termedia \& Banach

\begin{abstract}
Introduction: The vasospasm of carotid arteries is important for the progression of neurological sequelae. Many mechanisms have been found to be related to this clinical phenomenon. Predicting this event by using hematological biomarkers may provide opportunities for adopting preventive measures against unfavorable neurovascular complications. The aim of this study is to determine the hematological predictors of carotid artery vasospasm during carotid stenting.

Material and methods: A total of 120 patients who underwent carotid stenting were divided into two groups: those with and without carotid artery vasospasm. Carotid artery vasospasm was angiographically defined as transient or persistent emergent stenosis or irregularity of the vessel wall without evidence of thrombosis during carotid stenting. The hematological parameters were compared between 21 patients who developed carotid artery vasospasm (17.5\%) and 99 patients who did not (82.5\%).

Results: The mean age of the patients with carotid artery vasospasm and without carotid artery vasospasm was $66 \pm 8$ and $70 \pm 8$ years, respectively. Creatinine levels within 0.5-0.9 (OR $=3.704,95 \% \mathrm{Cl}: 1.245-11.019$, $p=0.019)$, each 1000 unit increase in neutrophil count $(\mathrm{OR}=1.567$, $95 \% \mathrm{Cl}: 1.027-2.392, p=0.037)$ and presence of diabetes $(\mathrm{OR}=3.081$, $95 \% \mathrm{Cl}: 1.116-8.505, p=0.030)$ were the independent predictors of carotid artery vasospasm in carotid arteries during carotid stenting.

Conclusions: The prediction of carotid artery vasospasm during carotid stenting should help clinicians adopt preventive measures against the development of neurological sequelae. This study found that creatinine levels, increased neutrophil count and presence of diabetes are independent predictors of carotid artery vasospasm.
\end{abstract}

Key words: hematological parameters, carotid artery stenting, carotid artery vasospasm.

\section{Introduction}

Vasospasm is one of the main factors complicating diseases that are mainly related to small vessels [1]. However, the spontaneous vasospasm of larger vessels is rare [2] and generally related to direct physical irritation of the endothelium [3], such as mechanical manipulations during operations or catheter applications [1]. Despite the technological improvements in endovascular interventions regarding safety and efficacy, vasospasm is still a major complication during these procedures [4].

Current literature data about carotid artery vasospasm are generally based on case reports, which mostly involve extracranial internal carotid

\author{
Corresponding author: \\ Dr. Yusuf Can \\ Department of Cardiology \\ University of Sakarya \\ Sakarya, Turkey \\ E-mail: dr.ycan@hotmail.com
}


artery stenosis [5]. The main reason for suggesting vasospasm as the underlying mechanism in these cases is the transient and recurring nature of this disorder. In most cases, stenosis resolves completely. Differential diagnosis of carotid vasospasm includes reversible cerebral vasoconstriction syndrome, primary angiitis of the central nervous system, arterial dissection, fibromuscular dysplasia and atherosclerosis, all of which cause stenosis in young patients without risk factors for stroke [6].

For decades, much effort has been exerted to determine the biochemical components of vasospasm, especially in stroke cases [7]. Previous studies have demonstrated that cellular adhesion molecules [8, 9], interleukin (IL)-6 [10], C3 and C4 complements [11], breakdown products of red blood cells and hemoglobin [12] are significantly related to vasospasm.

The aim of the current study is to evaluate the differences in the hematological parameters of patients with and without carotid artery vasospasm during carotid stenting.

\section{Material and methods}

A total of 120 patients were included in this study. The patients underwent carotid stenting between September 2010 and January 2015. Carotid artery vasospasm was angiographically defined as transient or persistent emergent stenosis or irregularity of the vessel wall without evidence of thrombosis during carotid stenting. Hematological parameters were compared between 21 (17.5\%) patients who developed carotid artery vasospasm and 99 (82.5\%) patients who did not. The complete blood count and serum biochemistry levels measured at the time of admission of the patients were obtained from the hospital records. The evaluated parameters were neutrophil-lymphocyte ratio, mean platelet volume, red cell distribution width, platelet distribution width, leucocyte count and monocyte count.

Patients with malignancies, chronic renal failure, chronic liver disease, hemoglobin values lower than $11 \mathrm{~g} / \mathrm{dl}$, white blood cell count higher than 11,000 cells $/ \mathrm{mm}^{3}$, having complications other than carotid artery vasospasm and using proximal protection device were excluded from the study.

The study was approved by the Sakarya University Faculty of Medicine Ethics Committee (Ethics Committee Number 71522473/050.01.04/137 and approval date: 25.03.2020).

\section{Statistical analysis}

Statistical analyses were performed using SPSS Statistics software version 17.0 for Windows (SPSS Inc., Chicago, IL, USA). The Kolmogor-
ov-Smirnov test was used to test the normality of data distribution. Descriptive statistics were presented as frequency and percent for categorical variables, and mean, standard deviation, median, minimum and maximum for numerical variables. Categorical data were compared between independent groups by the $\chi^{2}$ test, and numerical data were compared by either Student's $t$ test or the Mann-Whitney $U$ test, according to meeting the normal distribution criteria. To determine independent predictors of carotid artery vasospasm, multiple logistic regression analysis was performed by including the parameters which were significantly different between the patients with and without carotid artery vasospasm. Odds ratio (OR), 95\% confidence interval ( $\mathrm{Cl}$ ) values and their significance from multiple logistic regression analysis were reported.

\section{Results}

The study participants included 36 (30\%) females and 84 (70\%) males. There were 21 (17.5\%) patients who developed carotid artery vasospasm and 99 (82.5\%) patients who did not. The patients with carotid artery vasospasm and without carotid artery vasospasm were 48 to $87(66 \pm 8)$ and 48 to $90(70 \pm 8)$ years old, respectively. The age $(p=0.063)$ and gender $(p=0.714)$ distributions of the patients with and without carotid artery vasospasm were not statistically significant (Table I).

The presence of comorbidities in patients with and without carotid artery vasospasm are shown in Table I. Accordingly, the distributions of hypertension, coronary artery disease, smoking, cerebrovascular accident, peripheral artery disease and hyperlipidemia were similar between the groups, but the presence of diabetes was significantly higher $(p=0.019)$ in patients with carotid artery vasospasm (57.1\%) compared with patients without carotid artery vasospasm (30.3\%).

The stenosis in the carotid arteries is also presented in Table I. The distribution of the lateralization of stenosis between the two groups was similar ( $p=0.216)$, but patients with carotid artery vasospasm had a tendency to have stenosis in both carotid arteries and the patients without carotid artery vasospasm had more stenosis in the right carotid artery. When the groups were compared in terms of carotid stenting, both were found to have interventions in the right carotid artery (57.1\% and $55.6 \%$, respectively) and the distribution of the intervention side was similar in both groups $(p=0.156)$. Carotid artery spasm developed mainly after the dilatation procedure (66.7\% in cases, $61.6 \%$ in controls), but the distribution in the groups was similar $(p=0.328)$.

The results of the hematological and biochemical tests are shown in Table II. The comparisons 
Table I. Comparison of demographic characteristics between patients with carotid artery vasospasm and without carotid artery vasospasm

\begin{tabular}{|c|c|c|c|}
\hline Parameter & $\begin{array}{l}\text { With vasospasm } \\
\text { Mean } \pm \text { SD }\end{array}$ & $\begin{array}{c}\text { Without vasospasm } \\
\text { Mean } \pm \text { SD }\end{array}$ & $P$-value \\
\hline Age [years] & $66 \pm 8$ & $70 \pm 8$ & 0.063 \\
\hline Gender: & & & 0.714 \\
\hline Female & 7 (33.3) & $29(29.3)$ & \\
\hline Male & $14(66.7)$ & $70(70.7)$ & \\
\hline Hypertension & $19(90.5)$ & $80(80.8)$ & 0.362 \\
\hline Diabetes & $12(57.1)$ & $30(30.3)$ & 0.019 \\
\hline Coronary artery disease & 7 (33.3) & $30(30.3)$ & 0.785 \\
\hline Smoking & $5(23.8)$ & $21(21.2)$ & 0.793 \\
\hline Cerebrovascular accident & $21(100)$ & $98(99)$ & 1 \\
\hline Peripheral artery disease & $3(14.3)$ & $5(5.1)$ & 0.144 \\
\hline Hyperlipidemia & $9(42.9)$ & $32(32.3)$ & 0.355 \\
\hline Carotid artery: & & & 0.216 \\
\hline Right & $6(28.6)$ & $42(42.4)$ & \\
\hline Left & $5(23.8)$ & $29(29.3)$ & \\
\hline Both & $10(47.6)$ & $28(28.3)$ & \\
\hline Procedure: & & & 0.156 \\
\hline Right & $12(57.1)$ & $55(55.6)$ & \\
\hline Left & $7(33.3)$ & $42(42.4)$ & \\
\hline Both & $2(9.5)$ & $2(2)$ & \\
\hline Dilatation: & & & 0.328 \\
\hline Predilatation & $2(9.5)$ & $20(20.2)$ & \\
\hline Postdilatation & $14(66.7)$ & $61(61.6)$ & \\
\hline Both & $3(14.3)$ & $5(5.1)$ & \\
\hline
\end{tabular}

Continuous variables are presented as mean $\pm S D$, whereas categorical variables are presented as frequency (percentage).

revealed that the leukocyte $(p=0.042)$ and neutrophil counts $(p=0.018)$ were significantly higher in patients with carotid artery vasospasm and the creatinine levels were significantly lower in patients without carotid artery vasospasm $(p=0.037)$. The remaining biochemical and hematological evaluations were similar between the patients with and without carotid artery vasospasm.

To determine independent predictors of carotid artery vasospasm, multiple logistic regression analysis was performed by including the parameters which were significantly different between the patients with and without carotid artery vasospasm. The multiple logistic regression analyses revealed that creatinine levels within 0.5-0.9 $(\mathrm{OR}=3.704,95 \% \mathrm{Cl}: 1.245-11.019, p=0.019)$, each 1000 unit increase in neutrophil count $(\mathrm{OR}=1.567,95 \% \mathrm{Cl}: 1.027-2.392, p=0.037)$, and presence of diabetes $(\mathrm{OR}=3.081,95 \% \mathrm{Cl}$ : $1.116-8.505, p=0.030$ ) were independent pre- dictors of carotid artery vasospasm. The results of the multiple logistic regression analysis are shown in Table III.

\section{Discussion}

The primary aim of this study was to determine the independent predictors of carotid artery vasospasm development during carotid stenting in carotid artery. Creatinine levels between 0.5 and 0.9 , each $1000 \mathrm{U}$ increase in neutrophil count and presence of diabetes were found to be independent predictors of carotid artery vasospasm during carotid stenting.

The technological improvements in instruments and techniques for endovascular interventions have provided a significant safety and efficacy profile for these treatment options. Nevertheless, there are still some risks involved in these procedures. One of the most prominent complications is vasospasm. This phenomenon can be defined 
Table II. Comparison of hematological and biochemical parameters between patients with carotid artery vasospasm and without carotid artery vasospasm

\begin{tabular}{|c|c|c|c|}
\hline Parameter & $\begin{array}{l}\text { With vasospasm } \\
\text { Mean } \pm \text { SD }\end{array}$ & $\begin{array}{l}\text { Without vasospasm } \\
\text { Mean } \pm \text { SD }\end{array}$ & $P$-value \\
\hline Hemoglobin [g/dl] & $13.4 \pm 1.3$ & $13.1 \pm 1.3$ & 0.281 \\
\hline Hematocrit (\%) & $40.6 \pm 4.1$ & $39.6 \pm 4.1$ & 0.272 \\
\hline Leukocytes $\left[\times 10^{3} / \mu \mathrm{l}\right]$ & $8.1 \pm 1.4$ & $7.3 \pm 1.5$ & 0.042 \\
\hline Platelets $\left[\times 10^{3} / \mu \mathrm{l}\right]$ & $278.9 \pm 91.6$ & $240.5 \pm 58.8$ & 0.097 \\
\hline MPV [fl] & $7.9 \pm 0.9$ & $8 \pm 1.3$ & 0.696 \\
\hline RDW (\%) & $15.7 \pm 1.7$ & $15.4 \pm 1.4$ & 0.511 \\
\hline PDW [fl] & $17.8 \pm 0.9$ & $18 \pm 1.1$ & 0.289 \\
\hline Neutrophil $\left[\times 10^{3} / \mu \mathrm{l}\right]$ & $5.0 \pm 1.1$ & $4.4 \pm 1.3$ & 0.018 \\
\hline Lymphocyte $\left[\times 10^{3} / \mu \mathrm{l}\right]$ & $2.2 \pm 6.0$ & $2.2 \pm 7.6$ & 0.764 \\
\hline NLR & $2.4 \pm 0.9$ & $2.2 \pm 0.9$ & 0.179 \\
\hline Monocyte $\left[\times 10^{3} / \mu \mathrm{l}\right]$ & $0.5 \pm 0.3$ & $0.5 \pm 0.2$ & 0.941 \\
\hline Total cholesterol [mg/dl] & $183 \pm 41.2$ & $190.9 \pm 42.7$ & 0.614 \\
\hline Triglycerides [mg/dl] & $150.3 \pm 37.8$ & $162.5 \pm 71.8$ & 0.759 \\
\hline LDL-C [mg/dl] & $116 \pm 35.5$ & $124.2 \pm 37.3$ & 0.358 \\
\hline $\mathrm{HDL}-\mathrm{C}[\mathrm{mg} / \mathrm{dl}]$ & $37.7 \pm 9.8$ & $42.2 \pm 12.6$ & 0.139 \\
\hline Uric acid [mg/dl] & $5.5 \pm 1.5$ & $5.4 \pm 1.4$ & 0.677 \\
\hline Urea [mg/dl] & $35.7 \pm 8.3$ & $39.3 \pm 12.7$ & 0.300 \\
\hline Creatinine [mg/dl] & $0.9 \pm 0.2$ & $1 \pm 0.3$ & 0.037 \\
\hline
\end{tabular}

Continuous variables are presented as mean $\pm S D . M P V$ - mean platelet volume, RDW - red cell distribution width, PDW - platelet distribution width, NLR - neutrophil-lymphocyte ratio, LDL-C - low-density lipoprotein cholesterol, HDL-C - high-density lipoprotein cholesterol.

Table III. Independent predictors of carotid artery vasospasm in logistic regression model

\begin{tabular}{|lcccc|}
\hline Parameter & $P$-value & OR & \multicolumn{2}{c|}{$95 \mathrm{Cl}$ for OR } \\
\hline Creatinine (0.5-0.9) & 0.019 & 3.704 & 1.245 & 11.019 \\
\hline Neutrophil count & 0.037 & 1.567 & 1.027 & 2.392 \\
\hline Presence of diabetes & 0.030 & 3.081 & 1.116 & 8.505 \\
\hline
\end{tabular}

as the contraction of smooth muscle cells in the vessel walls. It may result in neurological deficits, particularly when occurring in the carotid arteries. To date, many studies have evaluated the mechanisms and treatment for vasospasm [13-18]. Some substances, such as cocaine [19], L-thyroxine [20] and nonsteroidal anti-inflammatory drugs [21], as well as mechanical irritations [22], have been found to be associated with vasospasm. Notably, for medium and large arteries such as the carotids, the sheer size of the catheter is an important factor, as it may induce vasospasm [3]. Determining the risk of carotid artery vasospasm in patients who should undertake carotid stenting is important for preventing the neurological deficits that may develop following possible vasospasm and stenosis in the carotid arteries.

Currently available data about the relationship between vasospasm and hematological markers are mainly based on research involving the cardiovascular system. Coronary artery spasm has been reported to be an important factor in the pathogenesis of ischemic heart diseases, which cover variant, effort and unstable anginas, as well as acute myocardial infarction and sudden death [23]. Previous studies have reported that elevated serum C-reactive protein levels [24], hyperlipidemia [25], and monocyte and polymorphonuclear cell counts [26] are related to vasospasm in the coronary arteries. Moreover, the inflammatory 
process and biological markers related to inflammatory responses, such as intercellular adhesion molecule-1 and vascular cell adhesion molecule-1, are reportedly associated with coronary vasospasm [27, 28].

Studies that have evaluated the role of hematological parameters in carotid artery vasospasm were mainly conducted in patients with stroke because internal carotid artery stenosis is a predisposing condition in $5-12 \%$ of all strokes [29]. Another field of related research is subarachnoid hemorrhages because vasospasm is the most common complication of these hemorrhages, leading to clinical deterioration [7]. All of these studies showed that biomarkers related to inflammation are the main factors that contribute to vasospasm in the aforementioned disease groups. Leucocytosis and fever [30, 31], cellular adhesion molecules [8, 9], IL-6 [10], C3 and C4 complements [11], breakdown products of red blood cells and hemoglobin [12] have been reported to be associated with vasospasm in carotid stenosis. Similarly, our study found that creatinine level, neutrophil count and presence of diabetes are related to carotid artery vasospasm.

The prediction of carotid artery vasospasm in the carotid arteries, particularly before endovascular interventions, has clinical importance for the adoption of preventive measures, especially against neurovascular complications. Intra-arterial mechanical irritations caused by distal protection devices, which are used in endovascular processes, carry their own vasospasm risks due to endothelial irritation and injury [32]. If it is possible to predict the additional individual risk of carotid stenosis over this treatment risk, additional steps can be taken to prevent this complication. The treatment for this complication includes nitroglycerine, calcium-channel blockers and papaverine [3, 33], as well as retrieval of the filter device [34]. Nitroglycerine is the preferred treatment option in these conditions, but it also has the risk of worsening hypotension, which may eventually cause adverse cardiac events [35]. Therefore, it would be reasonable to predict carotid artery vasospasm for the adoption of preventive measures, such as using a second-generation mobile-basket filter device instead of a first-generation fixed-basket filter device during endovascular interventions [34]. The former has been shown to be safer for these procedures [36].

In conclusion, carotid artery vasospasm and decreased distal blood flow cause neurological complications that are generally, but not always, reversible. Although reversible, some neurological sequelae may still develop. The hematologic biomarkers that can predict carotid artery vasospasm are particularly important for adopting preventive measures against these neurovascu- lar complications. In this context, we have found that creatinine levels within 0.5-0.9, each $1000 \mathrm{U}$ increase in neutrophil count and presence of diabetes were independent predictors of vasospasm during carotid stenting. We believe this report will contribute to the data in the literature and our results should be confirmed by further larger-scale studies.

\section{Conflict of interest}

The authors declare no conflict of interest

\section{References}

1. Dembo T, Tanahashi N. Recurring extracranial internal carotid artery vasospasm detected by intravascular ultrasound. Intern Med 2012; 51: 1249-53.

2. Mosso M, Jung HH, Baumgartner RW. Recurrent spontaneous vasospasm of cervical carotid, ophthalmic and retinal arteries causing repeated retinal infarcts: a case report. Cerebrovasc Dis 2007; 24: 381-4.

3. Coon AL, Colby GP, Mack WJ, et al. Treatment of mechanically-induced vasospasm of the carotid artery in a primate using intra-arterial verapamil: a technical case report. BMC Cardiovasc Disord 2004; 4: 11

4. Qureshi AI, Luft AR, Sharma M, Guterman LR, Hopkins LN. Prevention and treatment of thromboembolic and ischemic complications associated with endovascular procedures: Part II--Clinical aspects and recommendations. Neurosurgery 2000; 46: 1360-75.

5. Yoshimoto H, Asakuno K, Matsuo S, et al. Idiopathic carotid and coronary vasospasm: a case treated by carotid artery stenting. Surg Neurol Int 2014; 5 (Suppl 12): S461-4.

6. Yoshimoto H, Matsuo S, Umemoto T, Kawakami N, Moriyama T. Idiopathic carotid and coronary vasospasm: a new syndrome? J Neuroimaging 2011; 21: 273-6.

7. Jordan JD, Nyquist P. Biomarkers and vasospasm after aneurysmal subarachnoid hemorrhage. Neurosurg Clin N Am 2010; 21: 381-91.

8. Bavbek M, Polin R, Kwan AL, Arthur AS, Kassell NF, Lee KS. Monoclonal antibodies against ICAM-1 and CD18 attenuate cerebral vasospasm after experimental subarachnoid hemorrhage in rabbits. Stroke 1998; 29: 1930-5.

9. Tanriverdi T, Sanus GZ, Ulu MO, et al. Serum and cerebrospinal fluid concentrations of E-selectin in patients with aneurysmal subarachnoid hemorrhage. Brazil J Med Biol Res 2005; 38: 1703-10.

10. Gaetani P, Tartara F, Pignatti P, et al. Cisternal CSF levels of cytokines after subarachnoid hemorrhage. Neurol Res 1998; 20: 337-42.

11. Kawano T, Yonekawa Y. Serum complements as indicator for predicting vasospasm and its severity after aneurysmal subarachnoid hemorrhage. Nihon Geka Hokan 1990; 59: 189-97.

12. Zhang ZD, Yamini B, Komuro T, et al. Delayed clot removal and experimental vasospasm. Acta Neurochirur Suppl 2001; 77: 33-5.

13. Feng L, Fitzsimmons BF, Young WL, et al. Intraarterially administered verapamil as adjunct therapy for cerebral vasospasm: safety and 2-year experience. Am J Neuroradiol 2002; 23: 1284-90.

14. He GW, Fan KY, Chiu SW, Chow WH. Injection of vasodilators into arterial grafts through cardiac catheter to relieve spasm. Annals Thorac Surg 2000; 69: 625-8. 
15. Ito Y, Isotani E, Mizuno Y, Azuma H, Hirakawa K. Effective improvement of the cerebral vasospasm after subarachnoid hemorrhage with low-dose nitroglycerin. J Cardiovasc Pharmacol 2000; 35: 45-50.

16. Kaku Y, Yonekawa Y, Tsukahara T, Kazekawa K. Superselective intra-arterial infusion of papaverine for the treatment of cerebral vasospasm after subarachnoid hemorrhage. J Neurosurg 1992; 77: 842-7.

17. Yoshimura S, Tsukahara T, Hashimoto N, Kazekawa K, Kobayashi A. Intra-arterial infusion of papaverine combined with intravenous administration of high-dose nicardipine for cerebral vasospasm. Acta Neurochir 1995; 135: 186-90.

18. Mocco J, Mack WJ, Kim GH, et al. Rise in serum soluble intercellular adhesion molecule-1 levels with vasospasm following aneurysmal subarachnoid hemorrhage. J Neurosurg 2002; 97: 537-41.

19. Lange RA, Cigarroa RG, Yancy CW Jr, et al. Cocaine-induced coronary-artery vasoconstriction. N Engl J Med 1989; 321: 1557-62.

20. Hiasa Y, Ishida T, Aihara T, et al. Acute myocardial infarction due to coronary spasm associated with L-thyroxine therapy. Clin Cardiol 1989; 12: 161-3.

21. Mori E, Ikeda H, Ueno T, et al. Vasospastic angina induced by nonsteroidal anti-inflammatory drugs. Clin Cardiol 1997; 20: 656-8.

22. Ilia R, Cafri C, Jafari J, Weinstein JM, Abu-Ful A, Battler A. Prolonged catheter-induced coronary artery spasm mimicking fixed stenosis. Cathet Cardiovasc Diagn 1997; 41: 170-3.

23. Nakagawa H, Morikawa Y, Mizuno $\mathrm{Y}$, et al. Coronary spasm preferentially occurs at branch points: an angiographic comparison with atherosclerotic plaque. Circulation Cardiovasc Interv 2009; 2: 97-104.

24. Itoh T, Mizuno Y, Harada E, Yoshimura M, Ogawa H, Yasue $\mathrm{H}$. Coronary spasm is associated with chronic lowgrade inflammation. Circulation 2007; 71: 1074-8.

25. Tani S, Nagao K, Kawamorita T, Hirayama A. Association of the serum apolipoprotein levels with the occurrence of coronary vasospasm. Coron Artery Dis 2011; 22: 125-30.

26. Mahemuti A, Abudureheman K, Schiele F, et al. Association between inflammatory markers, hemostatic markers, and traditional risk factors on coronary artery spasm in patients with normal coronary angiography. J Interv Cardiol 2014; 27: 29-35.

27. Suzuki H, Kawai S, Aizawa T, et al. Histological evaluation of coronary plaque in patients with variant angina: relationship between vasospasm and neointimal hyperplasia in primary coronary lesions. J Am Coll Cardiol 1999; 33: 198-205.

28. Miwa K, Igawa A, Inoue H. Soluble E-selectin, ICAM-1 and VCAM-1 levels in systemic and coronary circulation in patients with variant angina. Cardiovasc Res 1997 36: 37-44.

29. Bates ER, Babb JD, Casey DE Jr, et al. ACCF/SCAI/SVMB/ SIR/ASITN 2007 Clinical Expert Consensus Document on carotid stenting. Vasc Med 2007; 12: 35-83.

30. McGirt MJ, Mavropoulos JC, McGirt LY, et al. Leukocytosis as an independent risk factor for cerebral vasospasm following aneurysmal subarachnoid hemorrhage. J Neurosurg 2003; 98: 1222-6.

31. Oliveira-Filho J, Ezzeddine MA, Segal AZ, et al. Fever in subarachnoid hemorrhage: relationship to vasospasm and outcome. Neurology 2001; 56: 1299-304.

32. Ohki T, Veith FJ. Critical analysis of distal protection devices. Semin Vasc Surg 2003; 16: 317-25.
33. Liu JK, Tenner MS, Gottfried ON, et al. Efficacy of multiple intraarterial papaverine infusions for improvement in cerebral circulation time in patients with recurrent cerebral vasospasm. J Neurosurg 2004; 100: 414-21.

34. Schirmer CM, Hoit DA, Malek AM. Iatrogenic vasospasm in carotid artery stent angioplasty with distal protection devices. Neurosurg Focus 2008; 24: E12.

35. Taha MM, Toma N, Sakaida H, et al. Periprocedural hemodynamic instability with carotid angioplasty and stenting. Surg Neurol 2008; 70: 279-85.

36. Vijayvergiya R, Otaal PS, Bagga S, Modi M. Symptomatic carotid vasospasm caused by a distal-protection device during stent angioplasty of the right internal carotid artery. Texas Heart Instit 2010; 37: 226-9. 